\title{
Hubungan Kompetensi Kewirausahaan Dan Kinerja Usaha: Studi Empiris UMKM Di Kota Tarakan
}

\author{
Nurjannatul Hasanah \\ nurjannatulh@yahoo.com \\ Mohamad Nur Utomo \\ mohnurutomo@gmail.com \\ Hariyadi Hamid \\ hariyadi.hamid@borneo.ac.id \\ Fakultas Ekonomi, Universitas Borneo, Tarakan
}

\begin{abstract}
Entrepreneurial success is determined by the competencies of an entrepreneur and will directly affect the success of business performance. This study aims to examine empirically the influence of entrepreneurial competencies on business performance. Entrepreneurship competency is measured by 15 indicators (Ability to control risk, autonomy, Search for and analyze information, Communication, Dynamic, Build social networks, Change management, Initiatives, Innovation, Integrity, Leadership, Results-oriented, Negotiation, Problem solving and Responsibility) While Business Performance is measured by 5 indicators (profit growth, sales growth, capital growth, efficiency and customer growth). The sample in this study was MSMEs in the city of Tarakan using a sample probability area sample method based on the subdistrict area. The data analysis technique uses the PLS-SEM method with the WarpPIs 6.0 application. The results of the study show that entrepreneurial competence has a positive impact on business performance. This study supports the RBV theory which states that a company's competitive advantage is generated from its unique resources.
\end{abstract}

Keywords: Entrepreneurship, Competence, MSMEs, Business Performance, City of Tarakan.

\section{PENDAHULUAN}

\section{Latar Belakang}

Pengembangan budaya kewirausahaan di dalam masyarakat sebagai alat dasar untuk membangun ekonomi dan sosial yang dapat meningkatkan daya saing suatu negara (Roblesa dan Rodrigueza, 2015). Menumbuh kembangkan kewirausahaan yang sukses menjadi sangat penting dalam menciptakan pertumbuhan ekonomi. Kesuksesan kewirausahaan ditentukan 
oleh kompetensi yang dimiliki seorang wirausaha. Kompetensi yang dimiliki oleh wirausaha akan mempengaruhi langsung keberhasilan kinerja usaha (Camuffo et al., 2012). Wirausaha yang memiliki kemampuan, pengetahuan, kreativitas, imajinasi, dan menangkap mudah sebuah peluang adalah faktor penting yang mempengaruhi keberhasilan usaha tidak hanya di tahap awal tetapi juga dimasa mendatang, dan hal tersebut menjadi insentif untuk mendorong menciptakan kekayaan wirausaha (Zahra et al., 2009). Beberapa penelitian terdahulu lainnya mendukung dan menunjukkan bahwa kompetensi kewirausahaan berpengaruh positif terhadap kinerja usaha (Barazandeh et al., 2015; Pamela et al., 2016; Ahmad et al., 2018).

Kompetensi kewirausahaan merupakan pengetahuan, sikap dan keterampilan yang terhubung satu dengan lainnya, yang diperlukan pengusaha untuk dilatih dan dikembangkan agar mampu menghasilkan kinerja terbaik dalam mengelola usahanya (Zuhriyah et al., 2013). Secara umum, kompetensi dikategorikan ke dalam pengetahuan, karakteristik dan keterampilan (Man et al., 2002). Sementara itu Kraus et al. (2012) mengkategorikan kompetensi kewirausahaan dalam dua konstruk yaitu 1) . keterampilan kewirausahaan (diukur dengan kemampuan yang dirasakan pengusaha dan peluang yang dirasakan) dan 2). kepribadian kewirausahaan (terdiri dari memiliki rasa tidak takut terhadap kegagalan dan entrepreneur's role models).

Selanjutnya Ahmad et al. (2018) menjelaskan kompetensi wirausaha yang diambil dari literatur manajemen dan kewirausahaan serta dapat diterapkan di berbagai sistem mulai dari yang sangat luas hingga yang lebih spesifik. Dimana terdapat empat aspek penting dari kompetensi yang juga merupakan definisi dari kompetensi tersebut yaitu sebagai berikut: (1). Kompetensi mencakup karakteristik keseluruhan individu yang terkait dengan kinerja efektifnya dari pekerjaan yang diberikan; (2). Kompetensi dimanifestasikan dalam perilaku individu, dan oleh karena itu bisa diamati dan terukur; (3). Kompetensi memfasilitasi pencapaian tujuan dan sasaran;(4). Kompetensi adalah sumber daya organisasi yang dapat dikembangkan.

Kemudian secara lebih lengkap Roblesa dan Rodrigueza (2015) meringkas 20 dimensi kompetensi wirausaha dari berbagai literatur yaitu sebagai berikut: kemampuan mengendalikan resiko, otonomi, mencari dan menganalisis informasi, kualitas pekerjaaan, komunikasi, percaya diri, membangun jaringan sosial, dinamis, manajemen perubahan, inisiatif, inovasi, integritas, leadhership, kontrol diri, beorientasi pada hasil, social mobility, kemampuan bernegosiasi, troubleshooting atau memiliki kemampuan menyelesaikan masalah, bertanggung jawab dan teamwork. Dengan demikian kompetensi kewirausahaan akan mempengaruhi kinerja 
bisnis oleh sebab itu penting untuk mengidentifikasi dan memahami dimensi-dimensi kompetensi kewirausahaan.

Penelitian ini bertujuan mengkaji secara mendalam hubungan dan pengaruh variabel kompetensi wirausaha terhadap kinerja usaha. Sampel dalam penelitian ini adalah UMKM di kota Tarakan dengan menggunakan metode sampel area probability sampleberdasarkan wilayah kecamatan. Hasil penelitian menunjukkan kinerja usaha ditentukan oleh kompetensi yang dimiliki oleh UMKM.

\section{TINJAUAN PUSTAKA}

Teori RBV menjelaskan bahwa keunggulan kompetitif suatu perusahaan dihasilkan dari sumber daya uniknya dimana sumber daya tersebut dapat berupa keterampilan manajemen, proses organisasi, dan pengetahuan yang bernilai, langka (unik), tidak dapat ditiru (tidak dapat dengan mudah dijual atau diperdagangkan), dan non-substitutable (Barney, 1991). Sumber daya penting tersebut adalah kompetensi kewirausahaan. Kewirausahaan secara luas merupakan salah satu poros menciptakan pertumbuhan ekonomi, melalui penciptaan kegiatan baru wirausaha mempromosikan perkembangan ekonomi sehingga pengusaha merupakan sumber daya strategis untuk organisasi dalam menghasilkan kinerja (Roblesa dan Rodrigueza, 2015).

Beberapa kajian empirik yang menunjukkan kompetensi kewirausahaan mempengaruhi kinerja usaha diuraikan berikut ini. Camuffo et al. (2012) melakukan penelitian untuk mengeksplorasi apakah dan sejauh mana portofolio kompetensi wirausaha mempengaruhi kinerja perusahaan. Penelitian ini menerapkan analisis statistik nonparametrik pada data hasil wawancara peristiwa perilaku dan survei dengan kuesioner pada sampel dari 53 pengusaha (perusahaan kecil) di Italia timur laut. Portofolio kompetensi sesuai dengan tiga dimensi:(1) portofolio kompetensi fungsional yang diambil dari penilaian diri; (2) portofolio kompetensi emosional yang diambil dari Emosi yang diadaptasi Inventarisasi Kompetensi; dan (3) portofolio kompetensi yang diambil dari BEI. Hasil penelitian menunjukkan bahwa kompetensi kewirausahaan dari masing-masing ke tiga dimensi memberikan hubungan yang berbeda terhadap kinerja perusahaan, sehinga hubungan kompetensi kewirausaan terhadap kinerja berpengaruh positif tetapi tidak linier.

Barazandeh et al. (2015) dalam studinya menganalisis hubungan antara kompetensi kewirausahaan, norma sosial dan kinerja bisnis pengusaha. 
Data dikumpulkan dari GEM (Global Entrepreneurship Monitor) pada tahun 2010 dengan menggunakn 125 kasus dipilih dari 59 negara meliputi Amerika Serikat, Rusia, Mesir, Afrika Selatan, Yunani, Belanda, Belgia, Prancis, Spanyol, Hongaria, Italia, Rumania, Swiss, Inggris, Denmark, Swedia, Norwegia, Jerman, Peru, Meksiko, Argentina, Brasil, Chili, Kolombia, Malaysia, Australia, Jepang, Korea, China, Turki, Pakistan, Iran, Tunisia, Ghana, Angola, Uganda, Zambia, Portugal, Irlandia, Islandia, Finlandia, Latvia, Montenegro, Kroasia, Slovenia, Bosnia dan Herzegovina, Makedonia, Guatemala, Kosta Rika, Bolivia, Ekuador, Uruguay, Azores, Vanuatu, Trinidad \& Tobago, Jamaika, Taiwan, Arab Saudi, dan Tepi Barat \& Jalur Gaza. Analisis faktor konfirmatori menunjukkan bahwa citra sosial pengusaha lebih tepat menggunakan indikator sikap nasional terhadap kewirausahaan untuk membangun "Norma sosial kewirausahaan". Sementara keterampilan kewirausahaan dan kepribadian kewirausahaan sebagai indikaor kompetensi kewirausahaan. Dan untuk kinerja menggunakan indikator pertumbuhan dan inovasi. Hasil penelitian menunjukkan pengaruh positif dari kompetensi kewirausahaan pada kinerja bisnis dan pengaruh positif norma sosial kewirausahaan terhadap kinerja dimediasi oleh kompetensi pengusaha.

Selanjutnya penelitian Pamela et al. (2016) menyajikan hasil dari wawancara mendalam dengan 105 peternak sapi perah di Kabupaten Malang, Jawa Timur. Berdasarkan hasil analisis disimpulkan bahwa kompetensi kewirausahaan responden berada pada level rendah yaitu keterampilan strategis, dan tingkat menengah pada kepemimpinan dan keterampilan manajemen teknis. Kompetensi wirausaha dihasilkan positif dari orientasi pribadi (minat peternak sapi perah dalam kegiatan kelompok, dan perilaku pengambilan risiko, dan karakteristik demografi). Hasil menunjukkan Kompetensi wirausaha memiliki hubungan positif terhadap kesuksesan bisnis. Minat peternak sapi perah dalam peningkatan kegiatan kelompok bisa menaikkan derajat orientasi pribadi, kompetensi kewirausahaan, dan kesusksesan bisnis. Berdasarkan kajian teoritik dan empirik yang dijelaskan sebelumnya maka dapat di rumuskan hipotesis sebagai berikut: Semakin meningkat kompetensi kewirausahaan semakin meningkat kinerja usaha.

\section{METODE PENELITIAN}

Dalam penelitian ini ada 2 variabel laten yang diamati dan di ukur yaitu kompetensi kewirausahaan sebagai variabel independen/eksogen, dan variabel kinerja usaha sebagai variabel dependen/endogen. Variabel dalam penelitian ini merupakan variabel laten / unobserved (tidak terukur) yang diproksikan menggunakan persepsi para responden dari indikator-indikator yang ditentukan. Penjelasan variabel penelitian dan indikator penelitian diuraikan dalam tabel berikut: 
Tabel 1

Variabel Penelitian dan Indikator Penelitian

\begin{tabular}{|c|c|c|c|}
\hline NO & Variabel Laten & Indikator Variabel & Sumber Acuan \\
\hline 1. & $\begin{array}{l}\text { Kompetensi Kewirausahaan } \\
\text { (Laten Eksogen) }\end{array}$ & $\begin{array}{ll}\text { 1. } & \text { Kemampuan mengendalikan } \\
& \text { resiko } \\
\text { 2. otonomi } & \\
\text { 3. } & \text { Mencari dan menganalisa } \\
\text { informasi } & \\
\text { 4. Komunikasi } \\
\text { 5. Dinamis } \\
\text { 6. Membangun jaringan sosial } \\
\text { 7. Manajemen Perubahan } \\
\text { 8. Inisiatif, } \\
\text { 9. Inovasi } \\
\text { 10. Integritas } \\
\text { 11. Leadhership } \\
\text { 12. Berorientasi pada hasil } \\
\text { 13. Negosiasi } \\
\text { 14. Kemampuan menyelesaikan } \\
\text { 15. } \\
\text { 15asalah } \\
\end{array}$ & $\begin{array}{l}\text { (Roblesa dan } \\
\text { Rodrigueza, 2015) }\end{array}$ \\
\hline 2. & $\begin{array}{l}\text { Kinerja Usaha } \\
\text { (Laten Endogen) }\end{array}$ & $\begin{array}{ll}\text { 1. } & \text { Pertumbuhan keuntungan } \\
\text { 2. } & \text { Pertumbuhan penjualan } \\
\text { 3. } & \text { Pertumbuhan Modal } \\
\text { 4. } & \text { Efisiensi } \\
\text { 5. } & \text { Pertumbuhan Pelanggan }\end{array}$ & $\begin{array}{l}\text { (Meutiaa dan Ismail, } \\
\text { 2012; Sidik, } 2012 \text { ) }\end{array}$ \\
\hline
\end{tabular}

Sumber: Teori dan studi empiris yang dikembangkan untuk penelitian ini

Populasi dan Sampel

Populasi dalam penelitian ini adalah seluruh UMKM yang ada di kota Tarakan. Sampel dalam penelitian ditentukan berdasarkan wilayah (area probability sample), dimana sampel ditentukan berdasarkan wilayah kecamatan yaitu kecamatan Tarakan Tengah, Tarakan Barat, Tarakan Timur dan Tarakan Utara. Sampel penelitian adalah para wirausaha UMKM menurut pengertian UUNomor 20 Tahun 2008 dan pengertian BPS. Teknik pengumpulan data menggunakan metode pengumpulan data primer. Studi lapangan dilaksanakan ke lokasi penelitian melalui cara penyebaran kuesioner, untuk keperluan analisis data. Sumber data berasal dari kuesioner yang diisi oleh responden (wirausaha/UMKM). Data dikategorikan menurut dimensi waktu sehingga data penelitian ini bersifat cross sectional. Berdasarkan pengumpulan data sampel dalam penelitian ini berjumlah 100 responden UMKM kota Tarakan.

Penelitian ini dianalisis dengan Partial Least Squares (PLS) - Structural Equation Modelling (SEM) menggunakan program WarpPLS versi 6.0 untuk menguji hipotesis.Pengujian analisis data meliputi pengujian pengukuran (validitas dan reliabilitas) uji Goodness of Fit dan pengujian hipotesis. 
Untuk menguji hipotesis yang diajukan dalam penelitian ini maka dapat dibuat persamaan model penelitian sebagai berikut:

$\operatorname{Kin}=\alpha+\beta$ Kom $+€$

Dimana, Kin = Kinerja Usaha, Kom= Kompetensi Kewirausahaan.

\section{HASIL PENELITIAN DAN PEMBAHASAN}

\section{Pengujian Model Pengukuran}

Pengujian model pengukuran bertujuan untuk menilai realibilitas dan validitas dari indikator-indikator pembentuk variabel laten dalam penelitian ini. Dimana secara konseptualisasi model seluruh variabel dalam model penelitian ini di ukur dengan indikator refleksif. Menurut Latan dan Ghozali (2016) untuk pengukuran realibilitas dan validitas (outer model) dengan variabel reklektif dengan melihat nilai dari:

1. Indicator reliability dengan nilai loading factor $>0,6$.

2. Internal consistency reliability dengan nilai composite reliability> 0,7.

3. Convergent validity dengan nilai Average Variance Extraced (AVE) > 0,5.

4. Discriminant validity dengan Akar kuadrat AVE > korelasi antar konstruk.

Maka berdasarkan rule of thumb pengukuran realibilitas dan validitas indikator-indikator variabel penelitian, dengan rincian lengkap nilai loading faktor, nilai composite reliability dan AVE variabel dapat disajikan pada Tabel 2.

\section{Tabel 2}

Nilai Loading Factor, Composite Reliability dan Average Variance Extract

\begin{tabular}{|lllllll|}
\hline Variabel & Indikator & & $\begin{array}{l}\text { Loading } \\
\text { Faktor }\end{array}$ & $\begin{array}{l}\text { Composite } \\
\text { Reliability }\end{array}$ & AVE \\
\hline $\begin{array}{l}\text { Kompetensi } \\
\text { Ke }\end{array}$ & Kemampuan & mengendalikan & & 0.91 & 0.532 \\
resiko & & & 0.765 & & \\
wirausahaan & Mencari & dan & menganalisa & & & \\
& informasi & & & 0.762 & & \\
\hline
\end{tabular}




\begin{tabular}{|lllll|}
\hline Variabel & Indikator & $\begin{array}{l}\text { Loading } \\
\text { Faktor }\end{array}$ & $\begin{array}{l}\text { Composite } \\
\text { Reliability }\end{array}$ & AVE \\
\hline \multirow{2}{*}{ Komunikasi } & 0.734 & & \\
& Dinamis & 0.662 & & \\
& Membangun jaringan sosial & 0.744 & & \\
& Leadership & 0.733 & & \\
& Negosiasi & 0.672 & & \\
& Kemampuan menyelesaikan & & \\
& masalah & 0.657 & & \\
& Bertanggung jawab & 0.754 & & \\
\hline Kinerja & Pertumbuhan keuntungan & 0.916 & 0.919 \\
Usaha & Pertumbuhan penjualan & 0.907 & & \\
& Pertumbuhan Modal & 0.858 & & \\
& Efisiensi & 0.723 & & \\
& Pertumbuhan Pelanggan & 0.745 & & \\
\hline
\end{tabular}

Sumber: Data primer yang diolah (2018)

Berdasarkan Tabel 2 dapat dilihat seluruh indikator dari item pembentuk variabel Kompetensi Kewirausahaan dan Kinerja Usaha adalah valid semua dengan memiliki nilai loading faktor di atas 0.6. Beberapa indikator variabel kompetensi kewirausahaan tidak diikut sertakan atau dihapus dalam analisis karena memiliki nilai loading factor dibawah 0,6. Dengan demikian seluruh indikator yang digunakan dapat dikatakan memiliki reliabilitas indikator yang baik. Dari hasil output di atas dapat dilihat bahwa nilai AVE untuk setiap variabel sangat baik yaitu $>0.5$ sehingga memenuhi kriteria validitas konvergen. Begitu juga dengan nilai Composite Reliability yang dihasilkan setiap variabel juga sangat baik yaitu $>0.7$ sehingga memenuhi reliabilitas konsistensi internal. Selanjutnya untuk hasil analis akar kuadrat AVE dibandingkan dengan korelasi antar konstruk dapat dilihat pada Tabel 3. 
Tabel 3

Nilai Akar Kuadrat AVE dan Korelasi Antar Variabel

\begin{tabular}{|l|l|l|l|}
\hline \multirow{2}{*}{ Konstruk } & \multirow{2}{*}{$\begin{array}{l}\text { AKAR KUADRAT } \\
\text { AVE }\end{array}$} & \multicolumn{3}{|l|}{ Correlations } \\
\cline { 3 - 4 } & & KW & KU \\
\hline Kompetensi Wirausaha & 0.729 & 1 & 0.586 \\
Kinerja Usaha & 0.834 & 0.586 & 1 \\
\hline
\end{tabular}

Sumber: Data primer yang diolah (2018)

Dari hasil output di atas dapat dilihat bahwa nilai akar kuadrat AVE untuk setiap variabel lebih besar dari korelasi antar variabel sehingga menunjukkan validitas dikriminan yang baik.

\section{Pengujian Model Struktural}

Pengujian model struktural (inner model) bertujuan untuk memprediksi hubungan antar variabel dengan melihat seberapa besar variance yang dapat dijelaskan dan mengetahui signifikan P-value (Latan dan Ghozali, 2016). Dengan demikian melalui evaluasi model struktural dapat menjawab pengujian hipotesis dalam penelitian ini.

Sebelum mengevaluasi hubungan antar variabel terlebih dahulu mengevaluasi goodness of fit dari model penelitian ini yang dapat dilihat outputnya pada Tabel 4 .

Tabel 4

Goodnes of Fit Model Structural

\begin{tabular}{|l|l|l|}
\hline Kriteria & Parameter & Rule Of Thumb \\
\hline Average path coefficient (APC) & $0.594 / \mathrm{P}<0.001$ & Acceptable $\mathrm{P}<0.05$ \\
\hline Average R-squared (ARS) & $0.353 / \mathrm{P}<0.001$ & Acceptable $\mathrm{P}<0.05$ \\
\hline $\begin{array}{l}\text { Average adjusted R-squared } \\
\text { AARS) }\end{array}$ & $0.346 / \mathrm{P}<0.001$ & Acceptable $\mathrm{P}<0.05$ \\
\hline $\begin{array}{l}\text { Average full collinearity VIF } \\
\text { (AFVIF) }\end{array}$ & 1.544 & $\begin{array}{l}\text { acceptable if }<=5 \text {, ideally }<= \\
3.3\end{array}$ \\
\hline
\end{tabular}




\begin{tabular}{|l|l|l|}
\hline Kriteria & Parameter & Rule Of Thumb \\
\hline Tenenhaus GoF (GoF) & 0.465 & $\begin{array}{l}\text { small }>=0.1 \text {, medium }>= \\
0.25, \text { large }>=0.36\end{array}$ \\
\hline Sympson's paradox ratio (SPR) & 1.000 & $\begin{array}{l}\text { acceptable if }>=0.7 \text {, ideally }= \\
1\end{array}$ \\
\hline $\begin{array}{l}\text { R-squared contribution ratio } \\
\text { (RSCR) }\end{array}$ & 1 & $\begin{array}{l}\text { acceptable if }>=0.9, \text { ideally }= \\
1\end{array}$ \\
\hline $\begin{array}{l}\text { Statistical suppression ratio (SSR) } \\
\text { causality }\end{array}$ & 1 & acceptable if $>=0.7$ \\
\hline $\begin{array}{l}\text { Nonlinear bivariate } \\
\text { direction ratio (NLBCDR) }\end{array}$ & 1 & acceptable if $>=0.7$ \\
\hline
\end{tabular}

Sumber: Data primer yang diolah (2018)

Berdasarkan Tabel 4 dapat dilihat model penelitian ini mempunyai fit yang baik, dimana nilai $\mathrm{P}$ value untuk APC, ARS dan AAR $<0.05$ dengan nilai APC = 0,594 , nilai $\mathrm{ARS}=0,353$ dan nilai $\mathrm{AARS}=0,346$. Begitu juga dengan nilai AFVIF yang dihasilkan yaitu < 3.3, yang berarti bahwa tidak ada masalah multikolonieritas antar indikator dan antar variabel eksogen. GoF yang dihasilkan yaitu 0,465> 0.36 yang berarti fit model sangat baik. Untuk SPR, RSCR, SSR dan NLBCDR menghasilkan nilai sama dengan 1, yang berarti tidak ada problem kausalitas didalam model (Latan dan Ghozali, 2016).

Selanjutnya untuk melihat hasil estimasi hubungan antar variabel serta besarnya variancedapat dilihat pada Tabel 5 .

Tabel 5.

Hasil Estimasi Hubungan Antar Variabel

\begin{tabular}{|l|l|l|l|l|}
\hline Description Path & $\begin{array}{l}\text { Path } \\
\text { Coefficient }\end{array}$ & P value & $\mathbf{R}^{2}$ & $\mathbf{Q}^{2}$ \\
\hline $\begin{array}{l}\text { Kompetensi Wirausaha --> Kinerja } \\
\text { Usaha }\end{array}$ & 0.594 & $<0.001$ & 0.353 & 0.352 \\
\hline
\end{tabular}

Sumber: Data primer yang diolah (2018) 
Berdasarkan Tabel 5 diperoleh nilai $R$-squared $\left(\mathrm{R}^{2}\right)$ untuk variasi yang mempengaruhi Kinerja Usaha sebesar 0,353 yang berarti bahwa pengaruh variasi variabel Kompetensi Wirausaha terhadap variasi Kinerja Usaha sebesar 35,3\% dan sisanya 64,7\% dipengaruhi variabel lain di luar model penelitian ini. nilai variasi $R$-squared $\left(\mathrm{R}^{2}\right)$ yang mempengaruhi Kinerja Usaha menunjukan dalam kategori moderat $\left(\mathrm{R}^{2}>0,25\right)$. (Latan dan Ghozali, 2016). Selanjutnya Nilai $Q$ Squared yang dihasilkan untuk Kinerja Usaha yaitu $0,352(>0)$, yang berarti bahwa model memiliki predictive relevance(Latan dan Ghozali, 2016).

Berdasarkan output pada Tabel 5dapat dilihat bahwa variabel Kompetensi Kewirausahaan berpengaruh positif signifikan terhadap Kinerja Usaha dengan nilai path koefisiennya sebesar 0.594 dan nilai $\mathrm{P}$-value $<0,01$. Dengan demikian hasil ini mendukung hipotesis, maka disimpulkan Hipotesis diterima.Hasil penelitian ini mendukung teori RBV yang menyatakan bahwa keunggulan kompetitif suatu perusahaan dihasilkan dari sumber daya uniknya yang merupakan kompetensi kewirausahan (Barney, 1991). Penelitian ini mendukung beberapa penelitian sebelumnya yang dilakukan oleh Camuffo et al. (2012), Barazandeh et al. (2015) dan Pamela et al. (2016) yang menyimpulkan kompetensi yang dimiliki wirausaha memberikan dampak yang positif terhadap kinerja usaha.

Dengan demikian semakin meningkat kompetensi kewirausahaan semakin meningkatkan kinerja usaha. Wirausaha dengan kompetensi antara lain mampu mengendalikan resiko dengan baik, selalu mencari dan menganalisa informasi peluang-peluang usaha baru, cakap dalam berkomunikasi, dinamis terbukti mampu mendorong kinerja usaha yang dijalankan (Roblesa dan Rodrigueza, 2015). Selain itu kinerja usaha dapat ditingkatkan dengan membangun jaringan sosial yang lebih luas, memiliki kepemimpinan dalam menjalankan usahanya, mampu bernegosiasi serta bertanggung jawab dan selalu dapat menyelesaikan masalah (Roblesa dan Rodrigueza, 2015). Diantara beberapa kompetensi tersebut terdapat 3 kompetensi yang paling besar sebagai penentu keberhasilan dan kesuksesan usaha yaitu pengendalian resiko yang baik, selalu mencari dan menganalisa informasi usaha dan memiliki tanggungjawab yang tinggi.

Penelitian ini membuktikan bahwa kompetensi kewirausahaan menjadi sangat penting dimiliki oleh wirausaha karena merupakan sumberdaya yang bernilai, langka (unik), tidak dapat ditiru (tidak dapat 
dengan mudah dijual atau diperdagangkan), dan non-substitutable. Hal tersebut menjadi keunggulan dan menciptakan kinerja.

\section{KESIMPULAN DAN SARAN}

\section{Kesimpulan}

Penelitian ini bertujuan menguji secara mendalam hubungan dan pengaruh variabel-variabel kompetensi wirausaha terhadap kinerja UMKM di kota Tarakan. Penelitian ini mengajukan hipotesis untuk menjawab masalah penelitian. Hasil pengujian hipotesis memberikan kesimpulan bahwa kompetensi kewirausahaan meningkatkan kinerja usaha. Dengan kata lain semakin meningkat kompetensi kewirausahaan semakin meningkat kinerja usaha. Hasil penelitian ini memberikan implikasi teoritis yaitu mendukung teori RBV yang menyatakan bahwa keunggulan kompetitif suatu perusahaan dihasilkan dari sumber daya uniknya yang merupakan kompetensi kewirausahan (Barney, 1991).

Berdasarkan hasil penelitian makaimplikasi praktis yang dapat disarankan dari hasil penelitian ini adalah bahwa kompetensi kewirausahaan harus dimiliki seorang wirausaha dan ditingkatkan karena terbukti mampu mendorong kesuksesan bisnis, kompetensi tersebut meliputi kemampuan mengendalikan resiko, mencari dan menganalisa informasi, kemampuan berkomunikasi, dinamis, membangun jaringan sosial, memiliki jiwa leadership, kemampuan bernegoisasi, Kemampuan menyelesaikan masalah dan bertanggung jawab.

\section{DAFTAR PUSTAKA}

Ahmad, N. H., Y. Suseno, P.-S. Seet, P. Susomrith, dan Z. Rashid. 2018. Entrepreneurial Competencies and Firm Performance in Emerging Economies: A Study of Women Entrepreneurs in Malaysia: Springer International Publishing.

Barazandeh, M., K. Parvizian, M. Alizadeh, dan S. Khosravi. 2015. "Investigating the effect of entrepreneurial competencies on business performance among early stage entrepreneurs Global Entrepreneurship Monitor (GEM 2010 survey data)". Journal of Global Entrepreneurship Research, Vol. 5, No. 18, hlm: 1-12.

Barney, J. 1991. "Firm resources and sustained competitive advantage". Journal of Management, Vol. 17, No. 1, hlm: 99-121. 
Camuffo, A., F. Gerli, dan P. Gubitta. 2012. "Competencies matter: modeling effective entrepreneurship in northeast of Italy small firms". Cross Cultural Management, Vol. 19, No. 1, hlm: 48-66.

Kraus, S., J. P. C. Rigtering, M. Hughes, dan V. Hosman. 2012. "Entrepreneurial orientation and the business performance of SMEs: a quantitative study from the Netherlands". Review Managerial Science, Vol. 6, No. 2, hlm: 161-182.

Latan, H., dan I. Ghozali. 2016. Partial Least Square Konsep, Metode dan Aplikasi Menggunakan WarpPLS 5.0. Semarang: Badan Penerbit Universitas Diponegoro.

Man, T. W. Y., T. Lau, dan K. F. Chan. 2002. "The competitiveness of small and medium enterprises A conceptualization with focus on entrepreneurial competencies". Journal of Business Venturing, Vol. 17, No. 2, hlm: 123142.

Meutiaa, dan T. Ismail. 2012. "The Development of Entrepreneurial Social Competence And Business Network to Improve Competitive Advantage And Business Performance of Small Medium Sized Enterprises: A Case Study of Batik Industry In Indonesia". Procedia - Social and Behavioral Sciences, Vol. 65, No., hlm: 46 - 51.

Pamela, R. Pambudy, dan R. Winandi. 2016. "Kompetensi Kewirausahaan Dengan Keberhasilan Usaha Peternak Sapi Perah Pujon, Malang". Jurnal Agribisnis Indonesia, Vol. 4, No. 1, hlm: 57-66.

Roblesa, L., dan M. Z. Rodrigueza. 2015. "Key Competencies for Entrepreneurship". Procedia Economics and Finance, Vol. 23, No., hlm: $828-832$.

Sidik, I. G. 2012 "Conceptual framework of factors affecting SME development: mediating factors on the relationship of entrepreneur traits and SME performance". Procedia Economics and Finance, Vol. 4, No., hlm: 373 383.

Zahra, S. A., I. Filatotchev, dan M. Wright. 2009. "How do threshold firms sustain corporate entrepreneurship? The role of boards and absorptive capacity". Journal of Business Venturing, Vol. 24, No., hlm: 248-260.

Zuhriyah, E., R. Murniningsih, dan R. Ningsih. 2013. Analisis Kompetensi Kewirausahaan, Orientasi Kewirausahaan, Dan Kinerja Perusahaan (Kasus Pada Umkm Pahat Batu Di Muntilan), edited by UMMGL. 